\title{
Biopolitics, complex systems theory and ecological social work: Conceptualising ways of transitioning to low carbon futures
}

Uschi Bay Faculty of Medicine Nursing and Health Sciences, Monash University, Australia

\begin{abstract}
INTRODUCTION: Social work is engaged with understanding and acting into change processes within society at various levels. How new social and environmental movements are conceptually framed can be usefully explored to enable new ways of understanding their role in change processes, particularly in addressing the most significant problem of our times, climate change and excessive non-renewable energy use.

METHODS: Complex systems theory and deep ecology are two of the theoretical conceptualisations that inform the Transition Town movement transnationally. Social workers share these two theoretical frameworks with the Transition Town movement as ways of thinking about effecting change processes. A brief introduction to a biopolitical lens, based on Lemke's reading of Michel Foucault is added to offer another way to conceptualise the movement's naturalistic logic.

CONCLUSION: A biopolitical lens seeks to make visible the precarious and contingent difference between nature and culture as well as politics and life. Biopolitical analytics aims to focus social workers on investigating the network of power relations, knowledge practices and modes of subjectification evident in change processes. The intersection of life and politics has transformed modern society and biopolitics aims to bring this into focus to understand what we are doing to ourselves.
\end{abstract}

KEYWORDS: Transition Town movement, biopolitics, complex systems theory, ecological social work, deep ecology

\section{Introducing the Transition Town movement}

The Transition Town movement aims to address climate change, peak oil and create local communities that are resilient and where people live happier lives despite economic austerity. The movement started in 2005 and is credited to Rob Hopkins, a permaculture teacher, who set out to develop an energy descent plan for Kinsale in Ireland. "His students Louise Rooney and Catherine Dunne are considered pioneers in that they presented the energy descent plan to Kinsale council who adopted it. Hopkins took this work to Totnes in the United Kingdom and set up the next transition town" (Bay, 2013, p. 172).

Totnes is considered the home of the Transition Network, a charitable organisation set up to inspire, support and train communities to organise themselves around the transition model. The Transition Handbook: from oil dependency to local resilience (Hopkins, 2008) has been a manual for grassroots communities around the world. This publication aims to "... support community-led responses to peak oil and climate change, building
AOTEAROA

NEW ZEALAND SOCIAL WORK 28(4), 89-99.

CORRESPONDENCE TO: Uschi Bay

uschi.bay@monash.edu 
resilience and happiness" (Hopkins \& Lipman, 2009, p. 7). Rob Hopkins (2008, p. 138) himself considered the movement "an emerging and evolving approach to community led sustainability". More recently, Hopkins has indicated the focus is more on facilitating a cultural shift than on it being an environmental movement. In short, the Transition Town movement is about mobilising "community actions and foster[ing] public empowerment and engagement around climate change, with the objective of catalysing a transition to a low carbon economy" (Seyfang, 2009, p. 2). The main message of the movement is that we must "reduce the already-dangerous amount of carbon in our atmosphere before temperatures increase too far and trigger feedback mechanisms" (Chamberlin, 2009, p. 18). Astyk (2007, n.p.) proposes that we can tackle peak oil and climate change by "living more simply, more frugally, using less, leaving reserves for others, reconnecting with our food and our community".

In November 2014, there were 472 official Transition Towns worldwide, 709 initiatives in over 34 countries (transitionnetwork. org). By April 2016, a total of 1258 initiatives were registered worldwide. There are 20 national hubs including Portugal, Germany, Japan, Ireland, Chile, Hungary, Belgium, Croatia, Spain, Denmark, Norway, France, Sweden, United States, Italy, Netherlands, Luxembourg, Romania, Brazil and Latvia. Australia and Aotearoa New Zealand do not have national hubs, although in Aotearoa New Zealand a website exists for the purpose of bringing national information together (transitiontowns.org.nz/national, 2016). In Australia, there are 51 officially registered Transition Town initiatives, the majority in the state of Victoria and New South Wales. In Aotearoa New Zealand, the official list has only six Transition Town initiatives listed. "However, the TT Aotearoa network provides information for nearly 60 transition groups that are currently active, or have been so in the past" (Cretney, Thomas, \& Bond, 2016, p. 84). Given the flexibility of small grassroots community groups, the official register may not be indicative of all the action that is being undertaken as part of the Transition Town movement or has ceased to be taken due to the many difficulties in maintaining grassroots activism. Specific examples of Transition Town projects in both Aotearoa New Zealand and Australia focus on seed banks, community gardens and alternative currencies; showing awareness raising films, exchanging of unwanted goods and holding festivals celebrating rivers; solar energy schemes and reskilling related to fixing machinery, bikes, bee keeping and teaching of skills to promote reusing and recycling household or personal items. A strong permaculture theme is also evident in the projects developed by Transition Town initiatives in both countries, not surprising given that the first descent plan in Kinsale emanated from a permaculture course taught by Rob Hopkins.

The principles that underpin the movement resonate with social work in many ways. First, the focus is on working for change rather than being against current wrongs. This kind of positive visioning is familiar to social workers who take a strengths-based or solution-focussed approach to their work with individuals, families, groups and communities, including policy communities (Corcoran, 2016). The second principle is to ensure people have access to good information and demonstrating confidence in the people to make good decisions. These principles fit well with promoting selfdetermination, a key component in social work ethics (see for example, the Australian Association of Social Workers, Code of Ethics, 2010). The third key principle the Transition Town movement seeks to apply is to be inclusive and open to difference, challenging an "us and them" position that leads to conflict and exclusion. The idea of the transition movement is to network and share experiences and knowledge. Like social work, the movement draws on many eclectic sources to build up a body of knowledge (Coady \& Lehmann, 2016). The strand of deep ecology social work and environmental social work both draw upon Indigenous 
knowledge and spirituality for connection to nature. These are also key ideas reflected in various aspects of the Transition Town movement, specifically the Heart and Soul groups now renamed inner transition (Besthorn, 2012; Coates, 2003; Gray, Coates, \& Hetherington, 2013). Fourth, building resilience is generally more confined in social work practice to capacity building, whereas the Transition Town movement also aims to strengthen food, energy and water systems as well as human resilience systems. The fifth principle of the Transition Network is to promote an inner and outer transition, a goal similar to social work practice informed by systems theory, where the interaction between individuals and their environment is a key focus for change (Connolly \& Harms, 2015). The sixth principle is to act on the idea that people can make changes and transform and build better lives by learning to support each other; to follow one's passion to create and innovate projects that can add to the whole change process overall. The seventh principle is to rely on the self-organisation of individuals and communities and on their decision-making capacities at the appropriate level, and by turning problems into solutions (Hopkins \& Lipman, 2009). This last point is also shared by social workers engaging in community development projects focussed on capacity building (Ife, 2016).

The processes for developing a Transition Town initiative are similar to the kinds of project and community development work that many social workers are trained to do (Ife, 2016). Firstly, a steering group is set up, awareness is raised by building networks with existing community groups and also to prepare for the launch of the initiative. Relevant sub groups are encouraged that deal with specific initiatives like seed saving, transport, solar or wind power, permaculture, recycling, upcycling, reusing, reskilling, for instance, learning how to keep bees. Using open space technology for running meetings to enable participation by all is an important way to encourage involvement in decision-making. Working with local councils to progress an energy descent plan is one of the key tasks proposed for each initiative, although not all initiatives take this step. These steps are not meant to be prescriptive, rather each group of committed and active members (transitioners) devise their own way of adapting these steps to suit their local setting, including any specific aspects that are required in relating to various arrangements to do with treaties, as in places like Aotearoa New Zealand. Within the movement, there is also an emphasis on honouring elders and their wisdom in having lived more frugal lives before the heavy reliance on fossil fuels. Practical lessons on how to reduce the carbon footprint through various means is encouraged (Transition Network, 2016a). These steps are not so much presented as a struggle against the State or against big industry, but as a way to envisage and imagine a future that is not reliant on increasing use of coal, gas and oil, instead aiming to value local communities and promote happier life styles. Enacting, modelling and enabling alternative lifestyles using fewer resources can be of value in addressing the way that community members are made aware of how to reduce their own carbon use on a daily basis.

\section{Transition as a new social movement}

The Transition Town movement working towards community change is a social movement that does not put political pressure on groups, nor participates in mainstream party politics by, for instance, directly supporting a green political party. Mostly, the movement aims to build a bridge to local government to promote community participation in decision-making to reduce carbon emissions and to plan for a better future. This focus on doing something positive rather than challenging dominant structures (Hopkins, 2008) has been critiqued for not adequately addressing the problem of climate change and peak oil at the structural and institutional level and for not addressing power relations in order to effect societal change (Connors \& McDonald, 2011). This 
issue impacts on members of transition initiatives as the tension between doing positive practical things at a local level and creating more self-reliant communities does not directly change the existing political and economic structures. Others argue that the experimentation and creativity involved in enacting the kind of world that transitioners hope to bring about is a kind of pre-figurative politics and does hold the possibility of transformative change (Cretney et al., 2016).

As Thompson (2002, p. 712) suggests social movements tend to "promote or resist change in society through people acting together in shifting circumstances". Thompson argues that a sociological perspective of new social movements since the 1960s influenced social work practice and laid the foundations for emancipatory practice (2002). Interestingly, he draws on Satre (1982), the French existentialist philosopher to characterise the type of relation among people in social movements as groups-in-fusions valuing the fluidity, fragmentation and non-institutionalisation of these groups in relation to the State. For this article, I will draw on some of Foucault's theorising, to explore the way his notion of biopolitics relates to complex systems theory and deep ecological social work theory in thinking about the Transition Town movement (Lemke, 2011).

I will highlight, based on Lemke (2011) three ways to think about biopolitics to enable social workers to reflect on the implications of transnational grassroots movements, like the Transition Town movement using complex systems theory, including the deep ecological lens. In biopolitical thinking, the relationship between biology or life processes and politics is hotly debated. Social workers are encouraged to consider what their starting point is in relation to the questions posed by biopolitical rationalities. Is it life that determines the basis of politics or is it that the object of politics is life? Lemke (2011) highlights three ways to think about biopolitics. The first is naturalism, the second is politicism and the third is interactionism. In naturalism, life is the basis of politics and the state is considered a living whole, like an organism, and politics is understood to be in reference to life and in this frame biology becomes the only legitimate description of reality (Morar \& Koopman, 2012). In politicism, life is the object and not the basis of politics and a dualism between human nature and society within a broader ecological framework is maintained. Lemke (2011) argues that Foucault was taking an interactionism approach of problematising the relationship between life; that he was concerned with the underlying logics of evolutionary life, and of politics. Foucault is not focussed on finding the biological determinants of politics, but emphasises the importance of historical political practices through which life emerges as the centre of political strategies. For Foucault (2003, p. 254), biopolitics "takes life as both its object and its objective". These values of life do not just drive state power but also oppositional movements and challenges to the state (Foucault, 1978). Both the state and oppositional movements are motivated by the value of life as an end itself. This value of life as an end in itself has many ethical and political implications that social workers can consider in exploring the way movements like the Transition Town movement develop and draw on knowledge practices, understand power relations and promote ways of being in the world.

Interestingly, fairly early on Foucault (1978, p. 143) stated, "modern man is an animal whose politics places his existence as a living being in question." Indeed, the Transition Town movement in aiming to address climate change and peak oil is posing the question of how the human species can survive carboniferous capitalism (Dalby, 2013). In this context, it is timely to think again about "what we are doing to ourselves in politicising life and biologising politics" (Lemke, 2011). The Transition Town movement aims to be pre-emptive in dealing with the impact of climate change and reduced availability of oil by facilitating local 
communities to take embodied responsibility and collectively explore ways of living that sustain life and even provide the conditions to thrive. It is worthwhile to aim to gain some conceptual clarity on the way the Transition Town movement is positioning itself in relation to complex systems theory and deep ecology and to consider what a biopolitical lens brings to the fore in these approaches to societal change.

\section{Complex systems theory}

The Transition Town movement is considered by several authors to frame its rationale within complex systems theory (Bailey, Hopkins, \& Wilson, 2010; Brunetta \& Baglione, 2013). Some of the key concepts drawn from complex systems theory by the movement are the notion of resilience, a term first formulated in ecological systems theory (Holling, 1973), which is related to the capacity for self-organisation and creative innovation. The notion of resilience promoted by Hopkins (2008) for the Transition Town movement is related to systems ecology, rather than the more dominant notion of engineering resilience which considers resilience as springing back after a shock or resistance to disturbances to an earlier state of equilibrium (Harrison, 2013). Ecological concepts of resilience are focussed on the interactions between different elements and multi-dimensional levels of systems. The emphasis is on resilience in the Transition Town movement by managing change not just by simply reacting to external shocks but by adapting, innovating and transforming life into "new more desirable configurations" (Folke, 2006, p. 259). Hopkins (2008, p. 134) promoted that "life with dramatically lower energy consumption is inevitable and it's better to plan for than to be taken by surprise". The notion of transitioning proclaims that experimentation with new systems of provision that cannot only withstand shocks such as peak oil, but develop beneficial connections within localised systems is necessary for all localities to be resilient and to avoid predictable vulnerabilities.
It is a key assumption of the Transition Town movement that local communities currently lack the resilience needed to deal with the adaption to climate change and that pre-emptive action needs to be taken to enable communities to deal with the changes to their food systems, transport and energy systems as oil becomes scarcer and the planet warms (Cretney et al., 2016). It is the relationship between the various elements that make up the industrial food system and the aim of re-localising food production informed by permaculture that are considered to enable new emergent possibilities that are not the properties of the parts of the system per se (see Hopkins, 2008). For example, transitioners planting berries and fruit trees (edible streetscapes) on the nature strip for school students to harvest while walking to and from school reflects a means to connect with school children about locally grown food and to offer free healthy food options, further implied in this project are also ideas about sharing and caring for others that show ways of being that are not based on market exchange and profits.

Social work identifies itself as a profession that works at these intersections between systems (micro, mezzo and macro) promoting interactions between various people, groups and institutions, by conceptually using ecological systems theory (Connolly \& Harms, 2015). There is a recognition of the complexity of these interrelationships and that these connections can be potentially beneficial (Zapf, 2009). In joining with the Transition Town movement, social workers can explore the multi-dimensional social systems aspects to the ecological notion of resilience, selforganisation and tighter feedback loops (because they are local and the results of actions are more directly apprehended), including increasing accountability for human actions. Some specific skills social workers can bring to the Transition Town movement are the capacity to undertake social impact assessments, social planning, community development processes and an understanding of urban governance. 
These skills are applicable for thinking through, researching and connecting various community members to design their own change processes (Dominelli, 2012). As there are at times core tensions around what "exactly constitutes the Transition Town model in any given place and how this effects progressive change" (Cretney et al., 2016, p. $85)$, social workers by drawing on the work of Paulo Freire (2000), can promote and encourage local communities to collectively investigate their conditions and explore ways of making changes to promote carbon emission reductions. In complex systems theory there are no simple answers on how to effect change. The capacity for reflexivity around these processes and also the use of social inquiry skills in collaboration with Transition Town groups may be another contribution social workers can make.

From a biopolitical perspective the development of local Transition Town initiatives can be thought about as the creation of loose networks between community members and others that aim to deal with contingency and non-linear evolutionary properties of complex systems, such as those predicted to occur with climate change and peak oil. Resilience within this mode of biopolitics is considered a preparatory measure that aims to manage risks, such as lack of food, loss of energy supplies and possible violent clashes between people seeking access to low levels of resources and to respond to such threats with complex adaptive systems that maintain species life. Transition Town initiatives from this perspective can be regarded as being part of new securitising strategies that responsibilise individuals to face the risks of climate change and peak oil and an uncertain future. In this sense, being part of new or (re)newing networks and engaging in selfgovernance is to build a form of localised contingent security against negative climate change impacts. The notion of networks and human securitising strategies highlights the potential for the Transition Town movement to focus narrowly on self-protection, local networks and neoliberal strategies for survival. To analyse the intersections of life and politics with neoliberal strategies and entrepreneurial practices can call on social workers to further investigate the power relations among these networks, the knowledge practices and the modes of subjectivation promoted to deal with these changes (Lemke, 2011).

\section{Deep ecological social work}

Ecological social work, specifically the deep ecology strand (Besthorn, 2012; Coates, 2003) can arguably be identified as taking a naturalism perspective on biopolitics, according to Lemke (2011). In naturalism, life is the basis of politics and the state is considered a living whole, like an organism, and politics is understood to be in reference to life and in this frame biology becomes the only legitimate description of reality (Morar \& Koopman, 2012). For instance, the current reliance on biological explanations of life processes as the basis for political decisionmaking has meant that the biological scientists had to prove global warming is occurring beyond any doubt. The Transition Town movement incorporates and advocates a deep ecology understanding of the cosmos, which does not separate humans and nature. Many deep ecologists, such as Joanna Macy, Arne Naess and John Seed are drawn on by the Transition Town movement to promote a change in the way community members relate to themselves and nature, to develop an ecological identity, an ecological self.

Deep ecological social workers argue for an ecological consciousness towards the planet by reconsidering the natural environment as finite, taking a holistic view of the human-nature relationship and including a key spiritual component that regards the universe in some sense as sacred (Coates, 2003; Zapf, 2009). For instance, Coates (2003) describes the Universe as an unfolding story in which human beings are a late arrival in the history of planet Earth. This story of the unfolding universe serves as the rationale for living human life in an ecologically conscious way and ecological biology is presented as 
offering values for living life that inhere objectively in nature. For Coates (2003), an ecological paradigm means recognition of: the interdependence between all (human and non-human species, nature and society), the self-organising capacities of systems and people, as individuating (including the capacity for self-realisation and the unique potential of each person, plant and species to flourish), for developing communality (self is in relationship to the whole) within a constantly changing and increasing complex Earth system (Coates, 2003, pp. 70-73). Conceptualising the connection between people and the trans-organic life of populations is associated in ecological social work with the idea of deep ecology, where ecology takes as its centre evolutionary histories of species and interactions with the planet as an ever-evolving ecological system (Coates, 2003).

Further, there is an assumption in the deep ecology paradigm that the environmental crisis equals a spiritual crisis (Coates, 2003, p. 87) and that "ecological destructiveness [of the planet and its biosphere] is [therefore] a failure of self-development" (Coates, 2003, p. 94). There are resonances of this kind of thinking, as Lemke (2011) indicated in the way that some religious groups incorporated biopolitics in the 1960s and 1970s by positing an organic understanding of reality and an interpretation of "man as a biospiritual unity whose life is set within cosmic nature, as well as within human history" (Cauthern, 1971, cited in Lemke, 2011, p. 25). This idea of humankind as located within cosmic nature resonates also with many holistic notions related to stewardship of the land that is evident in Australian Aboriginal cultures and Aotearoa New Zealand Māori traditional culture. These perspectives offer a "world view that integrates landscape, community, spirit and self. Life is a process of finding and expressing one's place in the cosmos, in the natural world to which we all belong" (Zapf, 2009, p. 181). The sacred, human beings belonging to the cosmos and daily life are not separated and the relationship to the land or Mother Earth is honoured.
The main method of self-realisation used in deep ecology is identification. "By recognising the intrinsic worth of other living beings, one recognises the solidarity of all life forms" (Keller, 2008, p. 207) and an expansionary sense of the self. If there are no boundaries and all boundaries between living beings are recognised as illusionary then harming Nature or any sentient beings is harming ourselves. To believe one is part of the rainforest means to protect it, this framing of the self is considered a spiritual change and one that has some similar ideas in Tibetan Buddhism and Transition Network training draws on for instance Joanna Macy's (2005) work, which promotes such a connection. The Norwegian philosopher Arne Naess, who is credited with deep ecological thinking developed an eight-point platform for political action and indicates Buddhism, secular philosophy and Christian principles as informing his approach (Besthorn, 2012; Keller, 2008). The link between a kind of cosmology and guardianship or stewardship of the planet Earth informs the kind of subjectivity that may be promoted within the Transition Town Movement's inner transition groups.

To transition and to become a transitioner a term used by Trainer (2010) to describe members of Transition Town initiatives is understood as a "really big process" (Marion, 2012, n.p.). Sophy Banks, one of the founders of the Transition Network in Totnes states:

Transition is the first thing that I came across that said our problem is not about carbon, our problem is not about energy, it's not about inequality, our problem is a whole worldview that creates a system of thought that creates outer systems and inner systems that are about separation and division and competition and so on. So for me, it was the first thing that said we have to put the whole system back together. We can't problem solve issueby-issue, we need to reimagine the whole thing and then just start building it. And my experience is that as soon as you do that, the whole way that you're thinking shifts (Banks, 2016, cited in Fabian, 2016). 
Usually, the focus in social work is more on psychological inner changes, whereas within the deep ecology frame transitioning is connected to a holistic ecological systems perspective that explores the place of people in the cosmos and within an unfolding story of the universe or as Zapf (2009, p. 179) puts it "people as place". There are tensions for some community members in some Transition Town Initiatives that relate to the focus on this kind of inner change and the perceived urgency and preference to do things and make practical changes in the world. The different styles and preferences of various transition initiative members often relate to this question of the relationship between nature and politics, with some seeking a new relationship with nature and community, while some are seeking to make political or practical changes collectively in the world now (Cretney et al., 2016).

Before exploring the notions of inner transition further, the biopolitical perspective on the naturalism evident in the deep ecology framework and offered as a way forward in addressing climate change and peak oil can be reconsidered in numerous ways. Here, I will limit myself to referring to Lemke's critique of naturalism. Lemke (2011) argues that this naturalism and the ecological form of biopolitics were overtaken by the development of bioscientific discoveries and technological innovations. The way that biotechnologies are applied blurs the distinction and intrinsic value of nature, technical solutions as well as the social and political processes. Ecological consciousness struggles to deal with these complexities, the blurring of the natural, societal and technological processes adding to the many challenges faced by humanity. The increasing capacity of human beings to manipulate the natural foundations of life blurs the distinction between the natural and artificial. According to Lemke (2011) this politicises the very concept of nature. A biopolitical lens makes this blurring a problematic aspect of the intersection between life and politics. Social workers can engage with these developments in biotechnologies and the implications for communities alongside the Transition Town movement members to aim to tease out the meaning of the obscuring of the natural, societal and technological in an effort to deal with these complexities. As Lemke (2011, p. 31), indicates:
the meaning of biopolitics lies in its ability to make visible the always contingent, always precarious difference between politics and life, culture and nature, between the realm of the intangible and unquestioned, on the one hand, and the sphere of moral and legal action on the other.

This biopolitical lens highlights that ecological consciousness is something that is no longer self-evident and has itself become problematic. The increasingly complex interactions between humans and nature and technology have brought and bring further and new challenges in dealing with climate change and peak oil.

\section{Inner transitioning}

In 2006 along with the Transition Town movement the notion of inner transition as a process began and attracted people to the movement that could assist with group facilitation, deepening self-knowledge and connection with nature, creating ceremonies and strengthening compassion, trust and acceptance (Fabian, 2016). The Transition Network offered assistance and training for new initiatives to develop processes for this inner transition. Each Transition Town initiative was encouraged to include a heart and soul group as part of its process, these groups are now called inner transition groups. A survey conducted by Sophy Banks (Transition Network) and Juliana Schneider (a student at Schumacher College) in 2012 indicated the diverse ways in which transition initiatives addressed and engaged with inner transition. Some read books together like the Macy Mondays (Joanna Macy) in London, some hosted events and promoted connection with nature. Macy 
(2005) a deep ecologist, activist, a systems theorist informed by Buddhism believes that healing the world and healing your heart and soul go hand in hand. The purpose of heart and soul groups was understood by surveyed members in several countries to build personal resilience (and deal with the perineal issue of burnout in voluntary community work), strengthening connection to nature, psychological and personal growth and also strengthening community resilience (Transition Network, 2016b).

From a biopolitical perspective, the subjectivation or as it is also sometimes called subjectification process through which one becomes a subject (Davies, 2006) is influenced by an on-going reflexivity required in negotiating power relations in society. Foucault maintained that modern power relations are productive in forming the subject, in that sense power is not something we are opposed to in making ourselves, but rather power relations form the condition of our existence. This does not mean that people are predetermined and inevitably shaped by their conditions; it simply means that agency is conditioned and that it requires reflexivity to critically investigate these conditions of our making within these power relations and practices.

Carbon intensive practices are not "something invented by the individual [her or] himself. They are models that he [she] finds in his [her] culture and are proposed, suggested, imposed by him [her] culture, his [her] society, his [her] social group" (Foucault, 1997, p. 291). Take for example the use of plane travel, there is a range of practices that promotes individuals to fly to various destinations for leisure, adventure, work as well as family and friendship connections. For instance, one of the strategies developed by the Edinburgh Transition Town initiative, in order to demonstrate to the Scottish Government that they were saving carbon from being emitted, was to ask people to pledge not to use planes to fly to various other destinations for a year. These pledges were then counted and reported to government as savings on carbon emissions and proof of moving towards a low carbon future (Aiken, 2016). Aiken was critical of the way the transition movement could be co-opted into taking such measurements to acquit themselves of drawing funding from the state by needing to meet such instrumentalist targets. This conduct of conduct carried out at a distance or arm's length from the state informs economic thinking that currently pervades all aspects of life, including securing life in the face of the risks associated with climate change.

\section{Conclusion}

In using a biopolitical lens, Foucault is not focussed on finding the biological determinants of politics, but rather is emphasising the importance of historical political practices through which life emerges as the centre of political strategies. Conceptualisation that facilitate political practices within the Transition Town movement are very diverse and in this article, I have focussed only on two theories, complex systems theory and deep ecology, that aim to promote an ecological consciousness that does not separate human being from nature and relies on the laws of nature to inform individual and collective living. The emphasis on the self-organising capacities of systems and people, including the capacity for self-realisation, resilience and the fulfilment of the unique potential of each person, that also allows each plant and species to flourish, is part of only one element in the movement for developing communality. These evolutionary and ecologically conceptions of life informed by permaculture and therapeutic practices are being used by the movement to reshape, reform and develop a renewed consciousness about people's relation to Nature. As Lemke (2011, p. 31) suggests, it may be important to use a biopolitical lens informed by Foucault to also continually make visible the way that there is always a precarious and contingent "difference between politics and life, culture and nature". When these distinctions are blurred 
through increasing uses of biotechnology and a (re)newed ecological consciousness these conceptions of our situation may affect the way we govern ourselves, others and the politics of living. Perhaps a biopolitical lens can assist social workers to continually make these differences visible and knowable and maybe one of our roles in contemporary social movements is to be able to explore and explain how historically situated practices have shaped our understanding of the interaction between life and politics. A biopolitical lens may allow us to engage in societal change processes with an eye to these complexities.

\section{References}

Aiken, G. T. (2016). Prosaic state governance of community low carbon transitions. Political Geography, 55, 20-29.

Astyk, S. (2007). The theory of anyway. Energy Bulletin, January 25. Retrieved from http://www.energybulletin. net/node/25115

Australian Association of Social Workers (2010). Code of Ethics. Canberra, Australia: Author.

Bailey, I., Hopkins, R., \& Wilson, G. (2010). Some things old, some things: The spatial representation and politics of change of the peak oil relocalisation movement. Geoforum, 41(4), 595-605. doi:10.1016/j. geoforum.2009.08.007

Bay, U. (2013). Transition town initiatives promoting transformational community change in tackling peak oil and climate change challenges. Australian Social Work, 66(2), 171-186. Retrieved from http://dx.doi.org.ezproxy. lib.monash.edu.au/10.1080/0312407X.2013.781201

Besthorn, F. (2012). Deep ecology's contribution to social work: A ten-year retrospective. International Journal of Social Welfare, 21(3), 248-259. doi:10.1111/j.14682397.2011.00850.x

Brunetta, G., \& Baglione, V. (2013). Resilience in the Transition Town movement. Towards a new urban governance. TEMA, 6(2), 251-264.

Chamberlin, S. (2009). The transition timeline: For a local, resilient future. Foxhole, Darlington, United Kingdom: Green Books.

ACKNOWLEDGEMENTS The author would like to thank the Faculty of Medicine, Nursing and Health Sciences at Monash University for financial support to enable data collection about Australian Transition Towns, as well as the editors and anonymous reviewers for their helpful comments on an earlier draft of this article.
Town Movement. Community Development Journal, 46(4), 558-572.

Corcoran, J. (2016). Solution-focused therapy. In N. Coady \& P. Lehmann (Eds.), Theoretical perspectives for direct social work practice: A generalist-eclectic approach, $3^{\text {rd }}$ ed.(pp. 435-452). New York, NY: Springer Publishing Company.

Cretney, R., Thomas, A., \& Bond, S. (2016). Maintaining grassroots activism: Transition Towns in Aotearoa. New Zealand Geographer, 72(2), 81-91.

Dalby, S. (2013). Biopolitics and climate security in the Anthropocene. Geoforum, 49, 184-192. Retrieved from http://dx.doi.org/10.1016/j.geoforum.2013.06.013

Davies, B. (2006). Subjectification: The relevance of Butler's analysis for education. British Journal of Sociology of Education, 27(4), 425-438.

Dominelli, L. (2012). Green social work: From environmental crisis to environmental justice. Cambridge, United Kingdom: Polity Press.

Fabian, R. (2016). Sophy Banks on the heart of transition. Kosmos Journal. June 14, 2016 Newsletter Online. Retrieved from https://www.kosmosjournal.org/news/ sophy-banks-on-the-heart-of-transition/

Folke, C. (2006). Resilience: The emergence of a perspective for social-ecological systems analyses. Global Environmental Change, 16(3), 252-267.

Foucault, M. (1978). The history of sexuality, Vol. 1: Ani. New York, NY: Pantheon Books.

Foucault, M. (1997). The birth of biopolitics. In P. Rabinow (Ed.), Ethics, subjectivity, and truth(pp. 73-79). New York, NY: New Press.

Foucault, M. (2003). Society must be defended: Lectures at the College de France. New York, NY: Picador Press.

Freire, P. (2000). Pedagogy of the oppressed. New York, NY: Continuum.

Gray, M., Coates, J., \& Hetherington, T.(Eds.). (2013). Environmental social work. New York, NY: Routledge.

Harrison, K. (2013). Building resilient communities. Journal of Media and Culture, 16(5). Retrieved from http:// journal.media-culture.org.au/index.php/mcjournal/article/ view/716

Holling, C. S. (1973). Resilience and stability of ecological systems. Annual Review of Ecology and Systematics, $4,1-23$.

Hopkins, R. (2008). The transition handbook: From oil dependency to local resilience. Totnes, Devon, United Kingdom: Green Books.

Hopkins, R., \& Lipman, P. (2009). Who we are and what we do. Transition Network.Org Retrieved from http:// transitionculture.org/wp-content/uploads/who_we_are_ high.pdf

Ife, J. (2016). Community development in an uncertain world: Vision, analysis and practice. Port Melbourne, VIC: Cambridge University Press.

Keller, D. R. (2008). Deep ecology: Encyclopedia of environmental ethics and philosophy. 2006-2011. Retrieved from http://www.uky.edu/OtherOrgs/AppalFor/ Readings/240\%20-\%20Reading\%20-\%20Deep\%20 Ecology.pdf

Lemke, T. (2011). Biopolitics: An advanced introduction. New York, NY: New York University Press. 
Macy, J. (2005). World as lover, world as self. Berkeley, CA: Parallax Press.

Marion (2012). Sophy banks on heart and soul groups. Transition Town Media. Retrieved from https:// transitiontownmedia.org/sophy-banks-heart-soul-groups/

Morar, N., \& Koopman, C. (2012). The birth of the concept of biopolitics: A critical notice of Lemke's biopolitics. Theory and Event, 15(4). The Johns Hopkins University Press. Retrieved December 16, 2016, from Project MUSE.

Satre, J. P. (1982). Critique of dialectical reason. London, United Kingdom: Verso.

Seyfang, G. (2009). Green shoots of sustainability: The 2009 UK transition town movement survey. University of East Anglia. Retrieved from http://www.transitionnetwork.org/ resources/gill-seyfang-green-shoots-sustainability-2009transition-movement-survey

Thompson, N. (2002). Social movement, social justice and social work. British Journal Social Work, 32(6), 711-722.

Trainer, T. (2010). The Transition Town movement: Its huge significance and a friendly criticism. Culture Change. Retrieved from http://www.culturechange.org/cms/ content/view/605/1/

Transition Network (2016a). Transition initiatives directory. Retrieved from http://www.transitionnetwork.org/ initiatives

Transition Network (2016b). The essential guide to doing transition. Retrieved from http://transitionnetwork.org/ resources/essential-guide-transition/

Transition Towns Aotearoa New Zealand (2014). What are transition towns? Retrieved from http://www.transitiontowns.org.nz/node/1667

Zapf, M. (2009). Social work and the environment: Understanding people and place. Toronto, ON: Canadian Scholars' Press. 